\title{
DESIGN DE TECNOLOGIAS ASSISTIVAS PARA TETRAPLÉGICOS
}

\author{
Beatrice Catarine Chagas Terço \\ Pontifícia Universidade Católica do Rio de Janeiro \\ biacinestesica@gmail.com \\ Luiza Novaes \\ Pontifícia Universidade Católica do Rio de Janeiro \\ Inovaes@puc-rio.br \\ João de Sá Bonelli \\ Pontifícia Universidade Católica do Rio de Janeiro \\ joao@muare.net
}

Resumo: Neste projeto de Iniciação em Desenvolvimento Tecnológico e Inovação, aprofundamos algumas questões teóricas a partir de um projeto de aplicação de Design de Interação, desenvolvido em parceria entre o Laboratório de Interfaces Físicas Experimentais (LIFE) desta universidade e usuários deficientes físicos. A proposta do projeto é desenvolver interfaces físicas que auxiliem pessoas que possuem limitação de movimento em suas ações cotidianas. A metodologia prático-experimental adotada suscita uma discussão em torno de temas como prática reflexiva, conceito proposto por Donald Schön; prática no design, por Cross; computação ubíqua, por Mark Weiser; e Interfaces Físicas (Physical Computing), por Dan O'Sullivan. A pesquisa abrange práticas participativas do Design em relação à sociedade, gerando inclusão social através da inovação tecnológica. Na primeira fase do projeto foram realizadas as etapas de observação e contato com usuários deficientes físicos, que determinaram algumas opções de desenvolvimento de projeto ligadas às limitações específicas de cada usuário. Destas opções foi escolhida a de desenvolvimento de um controle remoto adaptado, para uso de TV por indivíduos tetraplégicos. O controle se apresenta como o primeiro de uma série de objetos destinados a promover a liberdade e autonomia do deficiente físico no ambiente doméstico, e está em fase de testes. O projeto coloca em prática a parceria entre designer e deficiente físico em um processo de co-autoria no desenvolvimento de tecnologias assistivas.

Palavras-chave: Tecnologia Assistiva, Design de Interação, Ubiquidade, Design Participativo 